\title{
Fatty Acid Composition Indicates Two Types of Metabolic Syndrome Independent of Clinical and Laboratory Parameters
}

\author{
A. ŽÁK ${ }^{1}$, M. BURDA ${ }^{2}$, M. VECKA ${ }^{1}$, M. ZEMAN ${ }^{1}$, E. TVRZICKÁ ${ }^{1}$, B. STAŇKOVÁ $^{1}$ \\ ${ }^{1}$ Fourth Department of Medicine, First Medical Faculty, Charles University, General University \\ Hospital in Prague, Czech Republic, ${ }^{2}$ Institute for Research and Applications of Fuzzy Modeling, \\ Centre of Excellence IT4Innovations, University of Ostrava, Czech Republic
}

Received July 10, 2014

Accepted July 23, 2014

\section{Summary}

Dietary composition and metabolism of fatty acids (FA) influence insulin resistance, atherogenic dyslipidemia and other components of the metabolic syndrome (MS). It is known that patients with MS exhibit a heterogeneous phenotype; however, the relationships of individual FA to MS components have not yet been consistently studied. We examined the plasma phosphatidylcholine FA composition of 166 individuals (68F/98M) with MS and of $188(87 \mathrm{~F} / 101 \mathrm{M})$ controls. Cluster analysis of FA divided the groups into two clusters. In cluster 1 , there were $65.7 \%$ of MS patients and $37.8 \%$ of controls, cluster 2 contained $34.3 \%$ of patients and $62.2 \%$ of controls $(P<0.001)$. Those with MS within cluster 1 (MS1) differed from individuals with MS in cluster 2 (MS2) by concentrations of glucose $(P<0.05)$, NEFA $(P<0.001)$, HOMA-IR $(P<0.05)$, and levels of conjugated dienes in LDL $(P<0.05)$. The FA composition in MS1 group differed from MS2 by higher contents of palmitoleic (+30\%), $\gamma$-linolenic (+22\%), dihomo- $\gamma$-linolenic (+9\%) acids and by a lower content of linoleic acid $(-25 \%)$ (all $P<0.01$ ). These FA patterns are supposed to be connected with the progression and/or impaired biochemical measures of MS (lipolysis, oxidative stress, dysglycidemia, and insulin resistance).

\section{Key words}

Metabolic syndrome - Fatty acids • Delta desaturase activities • Cluster analysis

\section{Corresponding author}

A. Žák, Fourth Department of Medicine, First Medical Faculty, Charles University, General University Hospital in Prague, U Nemocnice 2, 12808 Prague 2, Czech Republic. E-mail: azak@vfn.cz

\section{Introduction}

Metabolic syndrome (MS) is one of the most important health issues in developed countries over recent decades. Its increasing prevalence ranges between 20-30\% in the middle aged (Bruce and Byrne 2009, Ervin 2009, Sethom et al. 2011). MS significantly increases the risk for cardiovascular diseases, type 2 diabetes mellitus and other diseases (neuropsychiatric disorders and some cancers) (Bruce and Byrne 2009).

MS represents a cluster of cardiovascular risk factors connected with insulin resistance, visceral obesity, disturbed glucose metabolism, atherogenic dyslipidemia and arterial hypertension. These components of MS are complemented with chronic low-grade inflammation, coagulopathy, endothelial dysfunction and oxidative stress. It is supposed that the link between visceral obesity and metabolic disturbances, such as insulin resistance, impaired secretion of insulin or dyslipidemia, is caused by dysregulation of FA metabolism and/or chronic low-grade inflammation of the adipose tissue (Kalupahana et al. 2012).

MS develops in consequence of an increased energy intake and physical inactivity resulting in overweight and obesity; other important factors include composition of the diet, aging of the population and genetic background (Bruce and Byrne 2009, Lottenberg et al. 2012, Murphy et al. 2013, Walsh et al. 2014).

Epidemiological data indicate that increased fat intake is connected with a higher prevalence of overweight and obesity. The individual components of MS are variably influenced by saturated fatty acids 
(SFA), monounsaturated fatty acids (MFA) and polyunsaturated fatty acids (PUFA) of n-3 as well as n-6 series, probably via their effects on plasma lipids (lipoproteins), blood pressure, insulin secretion and its action on target tissues and low-grade inflammation (Králová Lesná et al. 2013). Also, recent findings attribute an important influence on MS components to trans isomers of FA (Lottenberg et al. 2012).

Fatty acid profiles of individual lipid classes, especially those of cholesteryl esters and phosphatidylcholine, reflect dietary FA intake over several-weeks (i), FA metabolism (SFA synthesis, desaturation and elongation processes) (ii), as well as both enzymatic ( $\beta$-oxidation) and nonenzymatic (lipoperoxidation) degradation (iii). The resulting profiles of FA are also influenced by racial, ethnic, geographic, genetic factors and concomitant diseases (Hodson et al. 2008).

The FA profiles in MS are characterized by an increased content of SFA [especially palmitic acid (16:0)], palmitoleic (16:1n-7), $\gamma$-linolenic (18:3n-6) and dihomo- $\gamma$-linolenic (20:3n-6) acids, accompanied by a lower concentration of linoleic acid (18:2n-6). Moreover, there is enhanced activity of delta 9 desaturase (D9D, synonym for steraoyl-CoA desaturase 1, SCD-1) and delta 6 desaturase (D6D) together with lower activity of delta 5 desaturase (D5D) (Warensjö et al. 2005, Žák et al. 2007, Paillard et al. 2008, Kawashima et al. 2009, Mayneris-Perxachs et al. 2014).

Lower content of linoleic acid, higher ratios of both $\gamma$-linolenic and dihomo- $\gamma$-linolenic acids reflecting increased activities of $\mathrm{D} 6 \mathrm{D}$, as well as a decreased activity of D5D were described in obese children with other components of MS, but not in simple obesity. Analogous changes in FA profiles resembling insulin resistance were described in patients with recent myocardial infarction (Marangoni et al. 2014) and depressive disorder (Vařeka et al. 2012). FA profiles in adolescents with MS correlate not only with insulin resistance, but also with systemic markers of inflammation (Decsi et al. 2000, Klein-Platat et al. 2005). It must be stated that none of the cited papers have presented all these changes simultaneously.

Since MS is a heterogeneous group of diseases, with a different genetic background, as well as absence of a uniting definition based on various pathophysiological mechanisms (e.g. from interaction of genetic and environmental factors), the serum FA profile is not consistent. The aim of this study was to analyze the FA composition in the MS and control groups with the help of cluster analysis. We tried to characterize the patients with MS by cluster analysis of FA profile independently of clinical and laboratory parameters.

\section{Methods}

\section{Study design}

This study was carried out at the $4^{\text {th }}$ Department of Internal Medicine of General University Hospital from January 2009 to September 2013. The study protocol was approved by the Joint Ethical Committee of the General University Hospital and the $1^{\text {st }}$ Medical Faculty, Charles University in Prague. Written informed consent was obtained from all participants. In this period of time, a total of 354 persons were examined at the Lipid Clinic of the $4^{\text {th }}$ Department of Medicine, the $1^{\text {st }}$ Faculty of Medicine, Charles University and the General University Hospital in Prague.

\section{Participants}

The study group consisted of 188 (101 men and 87 women) controls (CON) and 166 patients (98 men and 68 women) with MS. MS were diagnosed according to the International Diabetes Federation criteria (Alberti et al. 2006). Combinations of individual MS components and their prevalence are shown in Table 1. All samples were marked with unique anonymized identification numbers, and the data was merged only after the assays had been completed.

The control group consisted of 42 healthy subjects ( 22 men and 20 women) that were recruited from employees of the General University Hospital, and 146 probands (79 men and 67 women) with at least one component of MS who failed to fulfil the diagnostic criteria for MS (see Table 1). None of control subjects was treated for dyslipidemia, hypertension or diabetes mellitus (prediabetic state, respectively).

Exclusion criteria for both groups were the following: current antioxidant, lipid-lowering and antidiabetic medication, excessive alcohol consumption (>30 g/day), hormonal replacement therapy, supplementation with polyunsaturated fatty acids (both of n-3 and n-6 families), manifestation of cardiovascular and/or cerebrovascular diseases, type 1 diabetes mellitus, liver (with exception of nonalcoholic fatty liver disease) and kidney diseases (creatinine $>130 \mu \mathrm{mol} / 1$ ), microalbuminuria (urinary albumin $30-300 \mathrm{mg} /$ day), 
hypothyroidism as well as recent infections and malignancies.

Table 1. Components of the metabolic syndrome in studied groups.

\begin{tabular}{ll} 
Control group $(\mathrm{n}=188)$ & \\
\hline without any component $^{a}$ & $42(22.3){ }^{\mathrm{b}}$ \\
$W$ & $44(23.4)$ \\
$T G$ & $11(5.8)$ \\
$H D L-C$ & $5(2.7)$ \\
$f_{S}-G$ & $4(2.1)$ \\
$W+T G$ & $42(22.3)$ \\
$W+B P$ & $22(11.7)$ \\
$W+f_{S}-G$ & $7(3.7)$ \\
$W+H D L-C$ & $6(3.2)$ \\
$B P+f_{S}-G$ & $5(2.6)$
\end{tabular}

Metabolic syndrome $(\mathrm{n}=166)$

$\begin{array}{ll}W+T G+H D L-C & 44(26.5) \\ W+T G+B P & 29(17.5) \\ W+T G+B P+f_{s-G} & 19(11.4) \\ W+T G+H D L-C+f_{s-G} & 18(10.8) \\ W+T G+f_{s-G} & 17(10.2) \\ W+B P+f_{s-G} & 13(7.8) \\ W+T G+H D L-C+B P & 12(7.2) \\ W+T G+H D L-C+B P+f_{s-} G & 11(6.6) \\ W+H D L-C+B P & 2(1.2) \\ W+H D L-C+f_{s-} G & 1(0.6)\end{array}$

a - presence (absence, respectively) of MS component(-s); b - number of cases (\%); fs-G - fasting serum glucose; BP blood pressure; $\mathrm{W}$ - waist circumference; TG - triglycerides; HDL-C - cholesterol in HDL. Metabolic syndrome: waist circumference $>94(88$, respectively) $\mathrm{cm}$ for men (women, respectively), and further at least 2 factors of following: triglycerides $>1.70 \mathrm{mmol} / \mathrm{l} ; \mathrm{HDL}-\mathrm{C}<1.04$ (1.29, respectively) $\mathrm{mmol} / \mathrm{l}$ for men (women, respectively); fasting serum glucose $\geq 5.60 \mathrm{mmol} / \mathrm{l}$ (or presence of diabetes mellitus type 2); elevated $\mathrm{BP}>130 / 85 \mathrm{~mm} \mathrm{Hg}$ (or antihypertensive therapy).

\section{Blood sampling}

Blood samples were taken after $12 \mathrm{~h}$ of fasting. Routine biochemical and hematological analyses were performed immediately; samples for special analyses were stored at $-70{ }^{\circ} \mathrm{C}$ until use.

\section{Dietary habits}

The nutritional intake of the main dietary components, based on a regular 7-day dietary questionnaire, was assessed in all study subjects. The nutritional data were analyzed by Nutrimaster SE software, version 1.0.

\section{Anthropometry}

Basal clinical and anthropometrical data, including assessment of body fat, were examined using standard methods, as described previously (Žák et al. 2007).

\section{Laboratory measurements}

Plasma concentrations of total cholesterol and triglycerides were measured by enzymatic-colorimetric methods (Boehringer, Mannheim, Germany). HDL-C was determined in the supernatant after precipitation of lipoproteins B by PTA/ $\mathrm{Mg}^{2+}$, using the kit from the same manufacturer. Concentration of apolipoprotein (apo) B was measured by a Laurell rocket electroimmunoassay using standard and specific antibodies (Behringwerke, Marburg, Germany). Immunoreactive insulin was determined by a RIA method using double monoclonal antibodies (Insulin IRMA, Imunotech Prague, Czech Republic). Concentrations of conjugated dienes in precipitated LDL (CD-LDL) were determined spectrophotometrically (Ahotupa et al. 1996). The concentrations of non-esterified fatty acids (NEFA) were determined by enzymatic-colorimetric method (NEFA, Randox Laboratories, U.K.).

Fatty acid patterns in main plasma lipid classes were examined by analytical procedures described previously (Tvrzická et al. 2002). The method variability presented as relative standard deviation (RSD) ranged from $1.07 \%$ for palmitic acid (16:0) to $8.60 \%$ for 16:1n-9. The relevant variability data (RSD) were for dihomo- $\gamma$-linolenic $1.25 \%$; stearic $0.76 \%$, myristic $8.06 \%$; docosahexaenoic $2.38 \%$; docosapentaenoic $1.91 \%$, and linoleic acids $0.725 \%$.

\section{Calculated parameters}

The Homeostasis model assessment method, HOMA-IR, was used as an index of insulin resistance (Matthews et al. 1985). Desaturase activities were estimated using FA product/precursor ratios (Žák et al. 2007).

\section{Statistical analyses}

Prior analyses, all data were cleaned and preprocessed: extreme values were examined and doublechecked. After that, a power-transformation was 
performed to achieve symmetry and constant variance. Data are expressed as mean and standard deviation or median and inter-quartile range (IQR, 25 $-75^{\text {th }}$ percentile) in cases of non-Gaussian distribution of data. Normality of the distribution was tested by the ShapiroWilks W test. Comparisons between the groups were carried out by the independent t-test, and the Wilcoxon test, respectively. P-value was adjusted for multiple comparisons using Benjamini-Hochberg correction.

\section{Cluster analysis}

Cluster analysis was performed in two steps. In the first step, the number of individual fatty acids in plasma phosphatidylcholine was reduced, and in the second step the grouping of subjects into the clusters was carried out.

To reduce number of individual fatty acids, a linear discriminant analysis was performed with stepwise forward variable selection, using the Wilk's lambda criterion: an initial model was created from the variable that mostly separated the groups. This model was then iteratively extended by including further variables depending on the Wilk's lambda criterion. Incorporation of additional variables stopped when the newly added variable did not show a statistically significant improvement $(\mathrm{P}>0.05)$. We used 22 initially analyzed FAs of all the probands to separate CON and MS groups using linear discriminant analysis. This resulted in overall $69.8 \%$ correct classification. Final correct classification was $74.5 \%$ for $\mathrm{CON}, 64.5 \%$ for $\mathrm{MS}$, respectively. Variables subjected into the linear discriminant analysis were dihomo- $\gamma$-linolenic $(20: 3 n-6 ; \quad F=30.41)$, stearic (18:0; $\quad \mathrm{F}=24.2)$, myristic (14:0; $\mathrm{F}=21.55)$, docosahexaenoic $(22: 6 n-3 ; \mathrm{F}=17.66)$, docosapentaenoic $(22: 5 n-3 ; \quad F=14.92)$, and linoleic $(18: 2 n-6, F=13.19)$ acids. These six individual fatty acids were included into the cluster analysis. On the selected six fatty acids, a hierarchical clustering was applied using the Ward's method with Euclidean measure (Ward 1963).

All the statistical analyses were performed using the R software version 3.1.0 (The R Development Core Team 2014).

\section{Results}

Basic clinical and biochemical parameters of the subjects with MS and in the CON group are shown in Table 2. As expected, subjects with MS differed from controls in nearly all parameters examined. There was no difference in sex ratio between MS and CON. Table 3 shows the composition of FA in plasma phosphatidylcholine and the corresponding derived parameters. In MS patients, significantly increased concentrations of palmitoleic (16:1n-7), stearic (18:0), dihomo- $\gamma$-linolenic (20:3n-6) acids, and the sum of SFA ( $\mathrm{SFA}$ ) were found. In contrast, patients with the MS had a decreased content of linoleic acid (18:2n-6), and the sum of PUFA n-6 (इPUFAn-6).

Table 2. Clinical and biochemical characteristics of the studied groups.

Metabolic
syndrome Controls

\begin{tabular}{|c|c|c|}
\hline Number of persons & 166 & 188 \\
\hline Gender $(M / F)$ & $98 / 68$ & $101 / 87$ \\
\hline Age (years) & $55.2 \pm 10.6^{\mathrm{a}}$ & $54.5 \pm 11.9$ \\
\hline Weight (kg) & $88.4 \pm 15.6^{\mathrm{a} * * *}$ & $77.4 \pm 14.4$ \\
\hline$B M I\left(k g . m^{-2}\right)$ & $29.8 \pm 4.0^{\mathrm{a}} * * *$ & $26.5 \pm 4.1$ \\
\hline Waist circumference $(\mathrm{cm})$ & $103 \pm 10^{\mathrm{a} * * *}$ & $91 \pm 12$ \\
\hline Systolic BP (mm Hg) & $141 \pm 17^{\mathrm{a} * * *}$ & $129 \pm 14$ \\
\hline Diastolic BP ( $\mathrm{mm} \mathrm{Hg})$ & $88 \pm 10^{\text {a } * * *}$ & $80 \pm 9$ \\
\hline Relative fat mass (\%) & $33.9 \pm 6.9^{\mathrm{a} * * *}$ & $30.0 \pm 7.6$ \\
\hline Fat mass (kg) & $29.8 \pm 7.6^{\mathrm{a}} * * *$ & $23.3 \pm 7.9$ \\
\hline Glucose (mmol/l) & $5.96 \pm 1.92^{\mathrm{a}} * * *$ & $4.99 \pm 1.27$ \\
\hline Insulin $(m U / l)$ & $10.70 / 7.24^{\mathrm{b} * * *}$ & $7.70 / 5.56$ \\
\hline HOMA-IR (ratio) & $2.59 / 2.14^{b * * *}$ & $1.62 / 1.20$ \\
\hline TC (mmol/l) & $6.42 \pm 1.43^{\mathrm{a} *}$ & $6.05 \pm 1.26$ \\
\hline$T G(\mathrm{mmol} / \mathrm{l})$ & $2.69 / 2.09^{b * * *}$ & $1.40 / 0.83$ \\
\hline$H D L-C(\mathrm{mmol} / \mathrm{l})$ & $1.27 \pm 0.35^{\mathrm{a} * * *}$ & $1.53 \pm 0.37$ \\
\hline NEFA $(\mathrm{mmol} / \mathrm{l})$ & $0.60 / 0.36^{\mathrm{b} * * *}$ & $0.53 / 0.36$ \\
\hline Apo B $(g / l)$ & $1.36 \pm 0.34^{\mathrm{a} * * *}$ & $1.21 \pm 0.37$ \\
\hline$C D-L D L(\mu \mathrm{mol} / \mathrm{l})$ & $66.7 / 23.7^{\mathrm{b} * * *}$ & $56.4 / 22.9$ \\
\hline
\end{tabular}

${ }^{a}$ - mean $\pm S D ;{ }^{b}-$ median/IQR. Statistical analysis: Student's t-test, or Wilcoxon test (in cases of non-Gaussian distribution of data); p-values were adjusted for multiple comparisons using Benjamini-Hochberg corrections: * $\mathrm{P}<0.05$, ** $\mathrm{P}<0.01$, *** $\mathrm{P}<0.001$. $\mathrm{M}$ - males; $\mathrm{F}-$ females; $\mathrm{BMI}$ - body mass index; $\mathrm{BP}$ - blood pressure; NEFA - nonesterified fatty acids; CD-LDL conjugated dienes in LDL; TC - total cholesterol; TG triglycerides; LDL - low density lipoproteins; HDL - high density lipoproteins; Apo - apolipoprotein; HOMA-IR - homeostasis model assessment for insulin resistance ( $f$-insulin $(\mu \mathrm{U} / \mathrm{ml}) \quad \mathrm{X}$ f-glucose $(\mathrm{mmol} / \mathrm{l}) / 22.5) ; \mathrm{IQR}$ - interquartile range.

A significant increase in activities of delta 9 desaturase for palmitoleic (D9D16) and delta 6 desaturase (D6D), as well as a decreased activity of delta 5 desaturase (D5D), were found in MS. 
Table 3. Plasma phosphatidylcholine fatty acid composition of the studied groups.

\begin{tabular}{|c|c|c|}
\hline Fatty acid $^{c}$ & $\begin{array}{l}\text { Metabolic } \\
\text { syndrome }\end{array}$ & Controls \\
\hline Number of persons & 166 & 188 \\
\hline $14: 0$ & $0.28 \pm 0.08^{\mathrm{a}}$ & $0.28 \pm 0.09$ \\
\hline 16:0 & $29.68 \pm 1.73^{\mathrm{a}}$ & $29.4 \pm 1.60$ \\
\hline $16: \ln -9$ & $0.11 \pm 0.03^{\mathrm{a}}$ & $0.11 \pm 0.03$ \\
\hline $16: \ln -7$ & $0.59 / 24^{\mathrm{b}^{* *} \mathrm{~g}}$ & $0.52 / 0.20$ \\
\hline $18: 0$ & $14.44 \pm 1.28^{\mathrm{a} * * *}$ & $13.84 \pm 1.14$ \\
\hline $18: \ln -9$ & $10.06 \pm 1.62^{\mathrm{a}}$ & $10.03 \pm 1.73$ \\
\hline $18: 1 n-7$ & $1.56 \pm 0.36^{\mathrm{a}}$ & $1.61 \pm 0.37$ \\
\hline $18: 2 n-6$ & $21.94 \pm 3.16^{\mathrm{a}^{* * *}}$ & $23.54 \pm 3.00$ \\
\hline $18: 3 n-6$ & $0.08 / 0.05^{\mathrm{b}}$ & $0.08 / 0.05$ \\
\hline $18: 3 n-3$ & $0.19 / 0.08^{b}$ & $0.21 / 0.10$ \\
\hline $20: \ln -9$ & $0.14 \pm 0.04^{\mathrm{a}}$ & $0.14 \pm 0.04$ \\
\hline $20: 2 n-6$ & $0.41 \pm 0.12$ & $0.40 \pm 0.11$ \\
\hline $20: 3 n-6$ & $3.35 \pm 0.70^{\mathrm{a}^{* * *}}$ & $2.98 \pm 0.56$ \\
\hline $20: 4 n-6$ & $10.99 \pm 2.05^{\mathrm{a}}$ & $10.91 \pm 1.83$ \\
\hline $20: 5 n-3$ & $0.94 / 0.50^{\mathrm{b}}$ & $0.92 / 0.48$ \\
\hline $22: 4 n-6$ & $0.31 \pm 0.08^{\mathrm{a}}$ & $0.32 \pm 0.07$ \\
\hline $22: 5 n-6$ & $0.20 \pm 0.06^{\mathrm{a}}$ & $0.20 \pm 0.05$ \\
\hline $22: 5 n-3$ & $0.90 \pm 0.18^{\mathrm{a}}$ & $0.91 \pm 0.17$ \\
\hline $22: 6 n-3$ & $3.56 \pm 1.11^{\mathrm{a}}$ & $3.36 \pm 0.95$ \\
\hline$\Sigma S F A$ & $44.47 \pm 1.68^{\mathrm{a} * * *}$ & $43.59 \pm 1.43$ \\
\hline$\Sigma M F A$ & $12.48 \pm 2.04^{\mathrm{a}}$ & $12.45 \pm 2.12$ \\
\hline$\Sigma P U F A$ n-6 & $37.22 \pm 3.20^{\mathrm{a}^{* *}}$ & $38.38 \pm 2.77$ \\
\hline$\Sigma P U F A n-3$ & $5.79 \pm 1.77^{\mathrm{a}}$ & $5.55 \pm 1.53$ \\
\hline$D 9 D 16^{d}$ & $0.020 / 0.008^{\mathrm{b}^{* *}}$ & $0.018 / 0.007$ \\
\hline$D 9 D 18^{e}$ & $0.700 \pm 0.120^{\mathrm{a}}$ & $0.730 \pm 0.150$ \\
\hline$D 6 D n \sigma^{e}$ & $0.004 / 0.003^{b^{* *}}$ & $0.003 / 0.002$ \\
\hline$D 5 D n \sigma^{f}$ & $3.45 \pm 1.08^{\mathrm{a}^{* *}}$ & $3.79 \pm 0.98$ \\
\hline
\end{tabular}

${ }^{a}-$ mean $\pm \mathrm{SD}(\mathrm{mol} \%) ;{ }^{\mathrm{b}}$ - median/IQR; ${ }^{c}$ - shorthand notation of fatty acids: number of carbon atoms: number of double bonds $\mathrm{n}$ - number of carbon atom from the methyl end to the nearest double bond. Only relevant fatty acids are presented; ${ }^{d}-$ D9D16, delta 9 desaturase for palmitoleic acid (16:1n-7/16:0); e - D9D18, delta 9 desaturase for oleic (18:1n-9/18:0); ${ }^{f}-$ D6D, delta 6 desaturase $(18: 3 n-6 / 18: 2 n-6) ; 9$ - D5D, delta 5 desaturase (20:4n-6/20:3n-6); statistical analysis: Wilcoxon test; $p$ - values were adjusted for multiple comparisons using Benjamini-Hochberg corrections: $* \mathrm{P}<0.05$, ** $\mathrm{P}<0.01$, $* * * \mathrm{P}<0.001$. IQR - interquartile range; $\Sigma$ SFA - total content (the sum) of saturated fatty acids; $\Sigma M F A$ - the sum of monounsaturated fatty acids; $\Sigma$ n- 6 PUFA - the sum of polyunsaturated fatty acids n-6 family; $\Sigma n-3$ PUFA - the sum of polyunsaturated fatty acids n-3 family.

Based on the cluster analysis that includes six selected FA obtained from linear discriminant analysis, two clusters were found both in the CON and MS groups. In the MS group, 109 patients $(65.7 \%)$ were classified as
Table 4. Clinical and biochemical characteristics of metabolic syndrome according to cluster analysis.

\begin{tabular}{|c|c|c|}
\hline & Cluster 1 & Cluster 2 \\
\hline Number of persons & 109 & 57 \\
\hline Gender $(M / F)$ & $67 / 42$ & $31 / 26$ \\
\hline Age (years) & $54.6 \pm 11.1^{\mathrm{a}}$ & $56.3 \pm 9.5$ \\
\hline Weight $(\mathrm{kg})$ & $89.9 \pm 15.7^{\mathrm{a}}$ & $85.5 \pm 15.0$ \\
\hline$B M I\left(k g \cdot m^{-2}\right)$ & $30.2 \pm 4.1^{\mathrm{a}}$ & $29.1 \pm 3.8$ \\
\hline Waist circumference (cm) & $104 \pm 11^{\mathrm{a}^{*}}$ & $101 \pm 9$ \\
\hline Systolic BP (mm Hg) & $141 \pm 15^{\mathrm{a}}$ & $142 \pm 15$ \\
\hline Diastolic BP (mm Hg) & $88 \pm 9^{a}$ & $89 \pm 10$ \\
\hline Relative fat mass (\%) & $33.3 \pm 6.8^{\mathrm{a}}$ & $35.3 \pm 6.9$ \\
\hline Fat mass $(\mathrm{kg})$ & $29.7 \pm 7.7^{\mathrm{a}}$ & $29.9 \pm 7.4$ \\
\hline \multicolumn{3}{|l|}{$\begin{array}{l}\text { Phenotypes of metabolic } \\
\text { syndrome }\end{array}$} \\
\hline$M S_{g l y}$ & $6(5.5)^{\mathrm{c}, \mathrm{d}^{*}}$ & $7(12.3)$ \\
\hline$M S_{\text {glylip }}$ & $50(45.9)$ & $16(28.1)$ \\
\hline$M S_{l i p}$ & $53(48.6)$ & $34(59.6)$ \\
\hline Glucose $(\mathrm{mmol} / \mathrm{l})$ & $6.24 \pm 2.22^{\mathrm{a}^{* *}}$ & $5.44 \pm 0.96$ \\
\hline Insulin $(m U / l)$ & $11.75 / 7.17^{\mathrm{b}}$ & $9.40 / 5.83$ \\
\hline HOMA-IR (ratio) & $3.03 / 2.30^{\mathrm{b}^{*}}$ & $2.07 / 1.94$ \\
\hline TC (mmol/l) & $6.51 \pm 1.53$ & $6.26 \pm 1.21$ \\
\hline$T G(\mathrm{mmol} / \mathrm{l})$ & $2.86 / 3.09^{b}$ & $2.43 / 1.60$ \\
\hline$H D L-C(\mathrm{mmol} / \mathrm{l})$ & $1.25 \pm 0.34$ & $1.30 \pm 0.36$ \\
\hline NEFA (mmol/l) & $0.69 / 0.73^{\mathrm{b}^{* * *}}$ & $0.44 / 0.40$ \\
\hline Apo B $(g / l)$ & $1.36 \pm 0.38$ & $1.36 \pm 0.26$ \\
\hline$C D-L D L(\mu \mathrm{mol} / \mathrm{l})$ & $70.9 / 34.9^{b^{*}}$ & $60.9 / 19.7$ \\
\hline
\end{tabular}

${ }^{a}-$ mean $\pm \mathrm{SD} ;{ }^{b}-$ median/IQR; ${ }^{c}-$ number of subjects (\%) in individual phenotypes of MS. Statistical analysis: Student's t-test, or Wilcoxon test (in cases of non-Gaussian distribution of data); $\mathrm{p}$ - values were adjusted for multiple comparisons using Benjamini-Hochberg corrections: * $\mathrm{P}<0.05$, $* * \quad \mathrm{P}<0.01$, $* * * \mathrm{P}<0.001{ }^{\mathrm{d}}-$ Fisher's exact test: $* \mathrm{P}<0.05$. Abbreviations: see Table 2. Characterization of metabolic syndrome phenotypes according to combination of metabolic syndrome components: $\mathrm{MS}_{\text {gly }}$ - increased waist, elevated BP (or hypertension), increased fasting serum glycemia; $\mathrm{MS}_{\text {lip }}$ - increased waist, elevated TG and/or decreased HDL-C, elevated BP (or hypertension) (alternatively); $\mathrm{MS}_{\text {glylip }}$ - increased waist, elevated TG and/or decreased $\mathrm{HDL}-\mathrm{C}$, increased fasting serum glycemia, elevated $\mathrm{BP}$ (alternatively).

cluster 1 (MS1) and 57 patients (34.3\%) were classified as cluster 2 (MS2). Conversely, in the control group, 71 probands $(37.8 \%)$ were classified as cluster 1 (CON1) and 117 subjects $(62.2 \%)$ were classified as cluster 2 (CON2). These results indicated a non-random distribution of subjects in both groups into cluster 1 and cluster $2\left(\chi^{2}=26.35 ; \mathrm{P}<0.001\right)$. This means that MS was present mainly in cluster 1 , while the CON probands presented mainly in cluster 2 . 
The basic clinical and biochemical characteristics of patients with MS according to cluster analysis are shown in Table 4. Patients in cluster 1 had a more detrimental metabolic profile in comparison with patients in cluster 2. There were no statistically significant differences between both clusters in sex ratio, age, BMI, fat mass, systolic and diastolic blood pressure, total cholesterol, HDL-C, triglycerides, and apoB concentrations. Between both clusters of MS, there was a non-random distribution of patients with different phenotypes of MS. In cluster 1, in comparison with cluster 2, the phenotype of MS with fasting hyperglycemia and dyslipidemia $\left(\mathrm{MS}_{\text {glyclip }}\right)$ was more prevalent $(\mathrm{P}<0.05)$. The patients with $\mathrm{MS}$ in cluster 1 (MS1) were characterized by increased waist circumference and HOMA-IR (both $\mathrm{P}<0.05$ ). Moreover, they had increased glucose $(\mathrm{P}<0.01)$, NEFA $(\mathrm{P}<0.001)$, and CD-LDL concentrations $(\mathrm{P}<0.05)$. There were no statistically significant differences in the concentration of hs-CRP (data not shown).

The plasma FA patterns, including derived parameters, of MS patients categorized according to cluster analysis are shown in Table 5. Apart from FAs used in the cluster analysis (see Table 5), the levels of palmitic (16:0), palmitoleic (16:1n-7), oleic (18:1n-9), vaccenic $\quad(18: 1 n-7), \quad \gamma$-linolenic $\quad(18: 3 n-6)$, eicosapentaenoic (20:5n-3), and arachidonic (20:4n-6) acids were increased in cluster 1 . In addition, patients in cluster 1 were characterized by higher activities of D9D for palmitoleic acid (D9D16), D9D for oleic acid (D9D18), and D6D. Contrary to the comparison of the whole MS with CON, there was no significant difference between cluster 1 and cluster 2 in the D5D activity.

In comparison of controls in cluster 1 (CON1) with those in cluster 2 (CON2) significantly increased BMI (27.5 \pm 4.5 vs $\left.25.9 \pm 3.7 \mathrm{~kg} / \mathrm{m}^{2}, \mathrm{P}<0.01\right)$, and waist circumference $(95.5 \pm 12.2$ vs $88.9 \pm 10.6 \mathrm{~cm}, \mathrm{P}<0.01)$ were found. After ANCOVA adjustment (with BMI and waist circumference as covariates), probands in CON1 had, in comparison with CON2, increased concentrations of palmitoleic $\quad(16: 1 \mathrm{n}-7) \quad(0.60 / 0.29 \quad$ vs $\quad 0.49 / 0.18$, median/IQR, mol\%, $\mathrm{P}<0.01)$, oleic (18:1n-9) $(10.14 \pm 2.30$ vs $9.57 \pm 1.91, \quad \mathrm{P}<0.01)$, and arachidonic $(20: 4 \mathrm{n}-6)$ $(11.66 \pm 1.91$ vs $10.46 \pm 1.62, \mathrm{P}<0.01)$ acids. In addition, higher contents of $\Sigma$ SFA $(44.48 \pm 1.68$ vs $43.10 \pm 1.43$, $\mathrm{P}<0.001), \Sigma \mathrm{MFA}(12.59 \pm 2.68$ vs $11.74 \pm 2.20, \mathrm{P}<0.001)$, $\Sigma$ PUFA n-3 $(5.76 \pm 1.50$ vs $4.88 \pm 1.42, \mathrm{P}<0.01)$, as well as a lower content of $\Sigma$ PUFA n-6 (36.69 \pm 3.36 vs $39.64 \pm 2.89, \mathrm{P}<0.001)$ were found. Similarly, probands in
Table 5. Plasma phosphatidylcholine fatty acid composition of metabolic syndrome according to cluster analysis.

\begin{tabular}{|c|c|c|}
\hline Fatty acid $^{c}$ & Cluster 1 & Cluster 2 \\
\hline Number of persons & 109 & 57 \\
\hline $14: 0^{h}$ & $0.28 \pm 0.08^{\mathrm{a}}$ & $0.28 \pm 0.08$ \\
\hline 16:0 & $29.89 \pm 1.87^{\mathrm{a} * *}$ & $29.29 \pm 1.34$ \\
\hline $16: \ln -9$ & $0.11 \pm 0.03^{\mathrm{a}}$ & $0.10 \pm 0.02$ \\
\hline $16: 1 n-7$ & $0.63 / 0.28^{b^{* * *}}$ & $0.48 / 0.18$ \\
\hline $18: 0^{h}$ & $14.59 \pm 1.34^{\mathrm{a}}$ & $14.16 \pm 1.12$ \\
\hline $18: \ln -9$ & $10.50 \pm 1.56^{\mathrm{a}}$ & $9.20 \pm 1.38$ \\
\hline $18: \ln -7$ & $1.62 \pm 0.38^{\mathrm{a} * * *}$ & $1.45 \pm 0.30$ \\
\hline $18: 2 n-6^{h}$ & $20.17 \pm 2.07^{\mathrm{a}}$ & $25.31 \pm 1.88$ \\
\hline $18: 3 n-6$ & $0.09 / 05^{b^{*}}$ & $0.07 / 0.04$ \\
\hline $18: 3 n-3$ & $0.20 / 0.08^{b}$ & $0.19 / 0.08$ \\
\hline $20: \ln -9$ & $0.14 \pm 0.05^{\mathrm{a}}$ & $0.13 \pm 0.03$ \\
\hline $20: 2 n-6$ & $0.42 \pm 0.13^{\mathrm{a}}$ & $0.40 \pm 0.10$ \\
\hline $20: 3 n-6^{h}$ & $3.45 \pm 0.70^{\mathrm{a}}$ & $3.16 \pm 0.68$ \\
\hline $20: 4 n-6$ & $11.34 \pm 2.03^{a^{* *}}$ & $10.34 \pm 1.95$ \\
\hline $20: 5 n-3$ & $1.09 / 0.49^{\mathrm{b}^{* * *}}$ & $0.80 / 0.28$ \\
\hline $22: 4 n-6$ & $0.32 \pm 0.08^{\mathrm{a}}$ & $0.29 \pm 0.06$ \\
\hline $22: 5 n-6$ & $0.21 \pm 0.06^{\mathrm{a}}$ & $0.18 \pm 0.05$ \\
\hline $22: 5 n-3^{h}$ & $0.94 \pm 0.19^{\mathrm{a}}$ & $0.82 \pm 0.13$ \\
\hline $22: 6 n-3^{h}$ & $3.76 \pm 1.18^{\mathrm{a}}$ & $3.20 \pm 0.85$ \\
\hline$\Sigma S F A$ & $44.85 \pm 1.84^{\mathrm{a}^{* * *}}$ & $43.79 \pm 1.04$ \\
\hline$\Sigma M F A$ & $13.08 \pm 1.96^{\mathrm{a}^{* * *}}$ & $11.40 \pm 1.74$ \\
\hline$\Sigma P U F A n-6$ & $35.84 \pm 2.79^{\mathrm{a}^{* * *}}$ & $39.70 \pm 2.28$ \\
\hline$\Sigma P U F A n-3$ & $6.19 \pm 1.95^{\mathrm{a}^{* * *}}$ & $5.07 \pm 1.06$ \\
\hline$D 9 D 16^{d}$ & $0.021 / 0.01^{\mathrm{b}^{* * *}}$ & $0.016 / 0.005$ \\
\hline$D 9 D 18^{e}$ & $0.726 \pm 0.120^{\mathrm{a}^{* *}}$ & $0.655 \pm 0.118$ \\
\hline$D 6 D n \sigma^{f}$ & $0.005 / 0.003^{\mathrm{b}^{* * *}}$ & $0.003 / 0.002$ \\
\hline$D 5 D n 6^{g}$ & $3.45 \pm 1.06^{\mathrm{a}}$ & $3.46 \pm 1.13$ \\
\hline
\end{tabular}

${ }^{a}-$ mean $\pm \mathrm{SD}(\mathrm{mol} \%) ;{ }^{\mathrm{b}}-$ median/IQR; ${ }^{\mathrm{c}}$ - shorthand notation of fatty acids: number of carbon atoms: number of double bonds $\mathrm{n}$ - number of carbon atom from the methyl end to the nearest double bond. Only relevant fatty acids are presented. ${ }^{d}-$ D9D16, delta 9 desaturase for palmitoleic acid (16:1n-7/16:0); e - D9D18, delta 9 desaturase for oleic $(18: 1 n-9 / 18: 0) ;{ }^{f}-$ D6D, delta 6 desaturase $(18: 3 n-6 / 18: 2 n-6) ; 9$ - D5D, delta 5 desaturase $(20: 4 n-6 / 20: 3 n-6)$; statistical analysis: Wilcoxon test; $\mathrm{p}$ - values were adjusted for multiple comparisons using Benjamini-Hochberg corrections: $* \mathrm{P}<0.05$, ** $\mathrm{P}<0.01$, $* * * \mathrm{P}<0.001 .^{\mathrm{h}}-$ Fatty acids used in cluster analysis separating MS patients into cluster 1 and cluster 2: dihomo- $\gamma$-linolenic $(20: 3 n-6)$, stearic $(18: 0)$, myristic (14:0), docosahexaenoic $(22: 6 n-3)$, docosapentaenoic (22:5n-3), and linoleic (18:2n-6) acids. Therefore, the respective $P$ values for these FAs are not indicated. IQR - interquartile range; $\Sigma$ SFA - total content (the sum) of saturated fatty acids; $\Sigma M F A$ - the sum of monounsaturated fatty acids; $\Sigma$ n- 6 PUFA - the sum of polyunsaturated fatty acids n-6 family; $\Sigma n-3$ PUFA - the sum of polyunsaturated fatty acids $n-3$ family. 
CON1 presented increased activities of $\mathrm{D} 9 \mathrm{D}$ for palmitoleic, $(0.020 / 0.010$ vs $0.017 / 0.06, \mathrm{P}<0.01)$, and D9D for oleic $(0.729 / 0.164$ vs $0.708 / 0.141, \mathrm{P}<0.05)$ acids, along with increased activity of D6D (0.004/0.003 vs $0.003 / 0.002, \mathrm{P}<0.001)$. The differences in FA profiles between cluster 1 and cluster 2 in $\mathrm{CON}$ group were similar to those observed for MS 1 and MS 2 cluster.

The control persons did not differ from the patients with MS in the daily energy intake, the energy content of proteins, fats as well as carbohydrates. No differences were observed in the intakes of dietary FA saturated FA, monounsaturated FA and PUFA (as sum of both n-3 and n-6 PUFA). Similarly, there were not statistically significant differences of macronutrients consumed in diets between the probands in cluster 1 and those in cluster 2 of MS (data not shown).

\section{Discussion}

The metabolic syndrome is a heterogeneous clustering of metabolic and non-metabolic abnormalities that are associated with various degrees of cardiovascular risk. Most clinical studies use either the diagnostic criteria according to ATP-III (NCEP Expert Panel, 2001), or those according to IDF (Alberti et al. 2006), which require the presence of central (abdominal) obesity and minimally two of four further risk factors (elevated glucose, triglycerides and arterial blood pressure, low HDL-C levels). Obesity is a key factor in the development of MS; increased body fat percentage unfavorably influences insulin resistance, oxidative stress and chronic systemic inflammation, as well as prothrombotic and proatherogenic metabolic traits (Phillips et al. 2013). In comparison with BMI, the values of waist circumference correlate more tightly with hemodynamic (blood pressure, endothelial dysfunction), hemostatic (coagulation, fibrinolysis), and metabolic parameters (plasma lipids, glucose, uric acid, insulin sensitivity) involved in MS (Savva et al. 2013). Visceral fat displays a high degree of lipolysis; it is almost exclusively perfused by the portal vein which delivers triglycerides, fatty acids and adipokines directly into the liver; this fact significantly influences hepatic metabolic processes (Carey 1998, Miranda et al. 2005).

Both definitions of MS, according to ATP-III and IDF, allow considerable inter-individual differences concerning the presence of the constitutive components (risk factors). In the German study PROCAM, for example, $72.9 \%$ of participants with MS had elevated blood pressure, $32 \%$ dyslipidemia with dysglycidemia, and $20 \%$ dyslipidemia without dysglycidemia (Assmann and Seedorf 2009). In our study, dyslipidemia (dyslipidemia with and without dysglycidemia) was almost twice more frequent in comparison with the PROCAM study. On the other hand, only $51.8 \%$ of patients in our MS group had elevated blood pressure (hypertension, respectively).

The $\mathrm{MS}_{\text {glylip }}$ phenotype (MS with dyslipidemia and dysglycidemia) is associated with high plasma concentrations of NEFA that point to insulin resistance of the adipose tissue. One Finnish prospective study has shown that increased NEFA levels predict the development of hyperglycemia and type 2 diabetes mellitus (Mahendran et al. 2013). Furthermore, elevated NEFA can contribute to low-grade systemic inflammation. In this study, we observed higher concentrations of CD-LDL in the MS group. The levels of CD-LDL partially reflect systemic oxidative stress and/or the presence of minimally modified LDL particles (Ahotupa et al. 1996). In our previous study, subjects with MS had low values of the antioxidative potential, mainly due to decreased activities of paraoxonase 1 (Vávrová et al. 2013).

To extend upon the investigations of visceral fat and NEFA concentrations, several recent clinical studies have concentrated on plasma fatty acid patterns. The spectrum of plasma FAs in MS depends both on the quality of dietary fat and on the metabolic processes (e.g. endogenous synthesis, activity of desaturases) that are partly influenced by the genotype (Hodson et al. 2008).

In this study, we performed a cluster analysis of FA profiles in plasma phosphatidylcholine for the participants of the MS and CON groups. Cluster analysis is a method for statistical data exploration that groups a set of probands in such a way that probands in the same group (called a cluster) are more similar to each other than to those in other groups (clusters). In our MS group, this analysis rendered two clusters independent of clinical and biochemical parameters, that were characterized by six FAs: dihomo- $\gamma$-linolenic (20:3n-6), stearic (18:0), myristic (14:0), docosahexaenoic (22:6n-3), docosapentaenoic (22:5n-3), and linoleic (18:2n-6) acids. In comparison with cluster 2 , cluster 1 displayed a higher consistency and a more adverse risk profile (waist circumference, HOMA insulin resistance index, concentrations of NEFA, glucose and CD-LDL). To our knowledge, this is the first phenotyping of MS based on cluster analysis of plasma FA. 
The FA profiles in cluster 1 differed from those in cluster 2 in higher proportions of $\Sigma$ SFA, $\Sigma$ MFA and $\Sigma$ PUFA n-3, while $\Sigma$ PUFA n-6 were decreased. Enhanced proportion of $\Sigma$ SFA was particularly due to palmitic (16:0) and stearic (18:0) acids, that of $\Sigma$ MFA to palmitoleic (16:1n-7), oleic (18:1n-9) and vaccenic (18:1n-7) acids; lower $\Sigma$ PUFA n-6 were caused by the drop in concentrations of linoleic acid (18:2n-6). The patients in cluster 1 had higher activities of D9D for palmitoleic acid, D9D for oleic acid and D6D. Elevated activities of D6D were connected with higher concentrations of $\gamma$-linolenic $(18: 3 n-6)$ and dihomo- $\gamma$ linolenic (20:3n-6) acids. Our previous study has shown significant positive correlations between the number of MS components and the concentrations of palmitic, palmitoleic, stearic and dihomo- $\gamma$-linolenic acids, as well as negative correlations for linoleic acid. $\Sigma$ SFA and activities of both D9D for palmitoleic acid and D6D correlated positively, इPUFA n-6 and activities of D5D negatively with the number of MS components (Žák et al. 2007). In several other studies, SFA, MFA, D9D and D6D correlated positively with cardiovascular risk factors (BMI, waist circumference, HOMA-IR, glycemia, triglycerides, blood pressure), while negative correlations were proved with both PUFA n-3 and n-6 series (Lee et al. 2008, Sethom et al. 2011, Mayneris-Perxachs et al. 2014). In a long-term prospective study, serum FA composition and activities of desaturases predicted the development of MS in middle-aged men (Warensjö et al. 2005).

The proportions of MFA, especially palmitoleic, oleic and vaccenic acids are indicators of de novo synthesis of FAs; higher concentrations of MFA were shown to predict an elevated risk of sudden cardiac arrest (Wu 2011). Increased level of palmitoleic acid was associated with enhanced lipogenesis induced by carbohydrates (Aarsland et al. 1997), as well as with hyperglycemia in Indian women in Peru (Lindgärde et al. 2006). Middle-aged Chinese with higher concentrations of palmitoleic acid in erythrocyte phospholipids had higher levels of several MS components and decreased concentrations of adiponectin (Zong et al. 2012).

We did not prove decreased concentrations of n-3 PUFA, which are - according to several authors associated with the progression of MS (Warensjö et al. 2006, Lee et al. 2008, Chien et al. 2011, Mahendran et al. 2013). On the contrary, a prospective Finnish study failed to prove any association between the incidence of MS and n-3 PUFA, while relative proportions of n-6 PUFA correlated negatively (Vanhala et al. 2012). In our study, elevated $\Sigma$ PUFA n-3 in cluster 1 can be explained by a more pronounced decrease in $\Sigma$ PUFA $n-6$, expressed in relative concentrations. A similar phenomenon was described for FA composition in patients with anorexia nervosa (Žák et al. 2005).

Decreased plasma concentrations of n-6 PUFA (mainly due to low concentrations of linoleic acid) as a hallmark of MS were observed in obese adults (Vessby 2003), children (Decsi et al. 2000), and postinfarction middle-aged men (Leskinen et al. 2005). Low concentrations of linoleic acid were found to be associated with the progression of MS (Laaksonen et al. 2002, Warensjö et al. 2006). The decrease in linoleic acid content can be explained by a higher degree of oxidative stress, lipoperoxidation, and synthesis of proinflammatory eicosanoids (Hardwick et al. 2013).

Patients with MS were shown to have increased activities of the enzyme stearoyl-CoA desaturase-1 (SCD1), synonym delta 9-desaturase (D9D). The preferred substrates for this enzyme are stearoyl-CoA and palmitoyl-CoA, which are converted to oleoyl-CoA (18:1n-9) and palmitoleoyl-CoA (16:1n-7), respectively. The human diet contains only very small amounts of palmitoleic acid, whereas oleic acid is usually present in abundance. In our study, activities of D9D for palmitoleic acid (D9D16) and D9Dfor oleic acid (D9D18) were significantly higher in cluster 1 than in cluster 2; high activities of D9D18 suggest a low dietary intake of fats rich in oleic acid. Increased activities of $\mathrm{D} 6 \mathrm{D}$ are associated with hyperinsulinemia and higher BMI (Decsi et al. 2000, Vessby 2003), while decreased activities of D5D, specific for MS, are independent of BMI and physical activity (Warensjö et al. 2005). In a group of Japanese men, low D5D activities predicted the development of abdominal obesity (Kawashima et al. 2009).

We did not prove statistically significant differences in dietary habits between MS and CON subjects, as well as between MS patients in cluster 1 and in cluster 2 . It is known that dietary assessment methods have many limitations. Among them, the most important are deficient data (e.g. finite food list, no quantification or imprecise estimation of portion size, absence of dietary details, underreporting of data), and the measurement error. The accuracy for individual dietary component reaches maximally 70 to $80 \%$ (Thompson and Subar 2013).

The limitations of our study are a relatively 
small number of participants and the cross sectional design. Estimated activities of desaturases are calculated as product/precursor ratio, reflecting both the metabolism of FAs and their dietary intake. For technical reasons, we did not estimate trans-FAs that are supposed to play an important role in the etiopathology of MS (Lottenberg et al. 2012). Among the strengths of our study is the fact that the participants with MS were not treated with lipid-lowering drugs, dietary supplements containing n-3 PUFA/n-6 PUFA, or antioxidants. The implementation of the cluster analysis of plasma FAs seems to be a promising approach to identify distinct phenotypes of MS.

\section{Conclusions}

By means of the cluster analysis of plasma FAs, MS can be categorized into two clusters, independent of clinical and biochemical parameters. These clusters differ in the biochemical abnormalities associated with insulin resistance, lipolysis, and oxidative stress, as well as in the degree of the risk for type 2 diabetes mellitus and cardiovascular disease. The results of this study warrant further research concerning dietary FA intake and genetic factors that influence FA metabolism. Improved understanding of fatty acid patterns in the pathogenesis of metabolic syndrome could lead to novel approaches in its prevention and treatment.

\section{Conflict of Interest}

There is no conflict of interest.

\section{Acknowledgements}

This research was supported by the grant NT/13199, IGA, Ministry of Health, the Czech Republic, RVO VFN64165/2012, PRVOUK P25/LF1/2, and by the European Regional Development Fund in the project of IT4 Innovations Centre of Excellence (CZ.1.05/1.1.00/02.0070, VP6).

\section{References}

AARSLAND A, CHINKES D, WOLFE RR: Hepatic and whole-body fat synthesis in humans during carbohydrate overfeeding. Am J Clin Nutr 65: 1774-1782, 1997.

AHOTUPA M, RUUTU M, MANTYLA E: Simple methods of quantifying oxidation products and antioxidant potential of low density lipoproteins. Clin Biochem 29: 139-144, 1996.

ALBERTI KG, ZIMMET P, SHAW J: Metabolic syndrome - a new world-wide definition. A consensus statement from the International Diabetes Federation. Diabet Med 23: 469-480, 2006.

ASSMANN G, SEEDORF U: High-density lipoprotein mutation. In: Clinical Lipidology: a Companion to Braunwald'S Heart Disease. CM BALLANTYNE (ed), Saunders Elsevier, Philadelphia, 2009, pp 85-92.

BRUCE KD, BYRNE CD: The metabolic syndrome: common origins of a multifactorial disorder. Postgrad Med J 85: 614-621, 2009.

CAREY DG: Abdominal obesity. Curr Opin Lipid 9: 35-40, 1998.

CHIEN KL, CHAO CL, KUO CH, LIN PH, LIU PH, CHEN PR, HSU HC, LEE BC, LEE YT, CHEN MF: Plasma fatty acids and the risk of metabolic syndrome in ethnic Chinese adults in Taiwan. Lipids Health Dis 10: 33, 2011.

DECSI T, CSÁBI G, TÖRÖK K, ERHARDT E, HAJNALKA M, BURUS I, MOLNÁR S, MOLNÁR D: Polyunsaturated fatty acids in plasma lipids of obese children with and without metabolic cardiovascular syndrome. Lipids 35: 1179-1184, 2000.

ERVIN RB: Prevalence of metabolic syndrome among adults 20 years of age and over, by sex, age, race and ethnicity, and body mass index: United States, 2003-2006. Natl Health Stat Report 5: 1-7, 2009.

HARDWICK JP, ECKMAN K, LEE YK, ABDELMEGEED MA, ESTERLE A, CHILIAN WM, CHIANG JY, SONG BJ: Eicosanoids in metabolic syndrome. Adv Pharmacol 66: 157-266, 2013.

HODSON L, SKEAFF CM, FIELDING BA: Fatty acid composition of adipose tissue and blood in humans and its use as a biomarker of dietary intake. Prog Lipid Res 47: 348-380, 2008.

KALUPAHANA NS, MOUSTAID-MOUSSA N, CLAYCOMBE KJ: Immunity as a link between obesity and insulin resistance. Mol Aspects Med 33: 26-34, 2012. 
KAWASHIMA A, SUGAWARA S, OKITA M, AKAHANE T, FUKUI K, HASHIUCHI M, KATAOKA C, TSUKAMOTO I: Plasma fatty acid composition, estimated desaturase activities, and intakes of energy and nutrient in Japanese men with abdominal obesity or metabolic syndrome. J Nutr Sci Vitaminol (Tokyo) 55: 400-406, 2009.

KLEIN-PLATAT C, DRAI J, OUJAA M, SCHLIENGER JL, SIMON CH: Plasma fatty acid composition is associated with the metabolic syndrome and low-grade inflammation in overweight adolescents. Am J Clin Nutr 82: 11781184, 2005.

KRÁLOVÁ LESNÁ I, SUCHÁNEK P, BRABCOVÁ E, KOVÁŘ J, MALÍNSKÁ H, POLEDNE R: Effects of different types of dietary fatty acids on subclinical inflammation in humans. Physiol Res 62: 145-152, 2013.

LAAKSONEN DE, LAKKA TA, LAKKA HM, NYYSSÖNEN K, RISSANEN T, NISKANEN LK: Serum fatty acid composition predicts development of impaired fasting glycaemia and diabetes in middle-aged men. Diabet Med 19: 456-464, 2002.

LEE E, LEE S, PARK Y: n-3 Polyunsaturated fatty acids and trans fatty acids in patients with the metabolic syndrome: a case-control study in Korea. Br J Nutr 100: 609-614, 2008.

LESKINEN MH, SOLAKIVI T, KUNNAS T, ALHO H, NIKKARI ST: Serum fatty acids in postinfarction middleaged men. Scand J Clin Lab Med 65: 485-490, 2005.

LINDGÄRDE F, VESSBY B, AHRÉN B: Serum cholesteryl fatty acid composition and plasma glucose concentrations in Amerindian women. Am J Clin Nutr 84: 1009-1013, 2006.

LOTTENBERG AM, AFONSO MDA S, LAVRADOR MS, MACHADO RM, NAKANDAKARE ER: The role of dietary fatty acids in the pathology of metabolic syndrome. J Nutr Biochem 23: 1027-1040, 2012.

MAHENDRAN Y, CEDERBERG H, VANGIPURAPU J, KANGAS AJ, SOININEN P, KUUSISTO J, UUSITUPA M, ALA-KORPELA M, LAAKSO M: Glycerol and fatty acids in serum predict the development of hyperglycemia and type 2 diabetes in Finnish men. Diabetes Care 36: 3732-3738, 2013.

MARANGONI F, NOVO G, PERNA G, PERRONE FP, PIRELLI S, CEROTI M, QUERCI A, POLI A: Omega-6 and omega-3 polyunsaturated fatty acid levels are reduced in whole blood of Italian patients with a recent myocardial infarction: the AGE-IM study. Atherosclerosis 232: 334-338, 2014.

MATTHEWS DR, HOSKER JP, RUDENSKI AS, NAYLOR BA, TREACHER DF, TURNER RC: Homeostasis model assessment: insulin resistance and beta-cell function from fasting plasma glucose and insulin concentrations in man. Diabetologia 28: 412-419, 1985.

MAYNERIS-PERXACHS J, GUERENDIAIN M, CASTELLOTE AI, ESTRUCH R, COVAS MI, FITO M, SALASSALVADÓ J, MARTINEZ-GONZALES MA, AROS F, LAMUELA-RAVENTÓS RM, LÓPEZ-SABATER MC, FOR PREMIDED STUDY INVESTIGATORS: Plasma fatty acids composition, estimated desaturase activities, and their relation with the metabolic syndrome in a population at high risk of cardiovascular disease. Clin Nutr 33: 90-97, 2014.

MIRANDA PJ, DEFRONZO RA, CALIFF RM, GUYTON JR: Metabolic syndrome: definition, pathophysiology, and mechanisms. Am Heart J 149: 33-45, 2005.

MURPHY R, CAROLL RW, KREBS JD: Pathogenesis of the metabolic syndrome: Insights from monogenic disorders. Mediators Inflamm 2013: ID 920214, 2013.

PAILLARD F, CATHELINE D, DUFF FL, BOURIEL M, DEUGNIER Y, POUCHARD M, DAUBERT JC, LEGRAND P: Plasma palmitoleic acid, a product of stearoyl-CoA desaturase activity, is an independent marker of triglyceridemia and abdominal adiposity. Nutr Metab Cardiovasc Dis 18: 436-440, 2008.

PHILLIPS CM, TIERNEY AC, PEREZ-MARTINEZ P, DEFOORT C, BLAAK EE, GJELSTAD IM, LOPEZMIRANDA J, KIEC-KLIMCZAK M, MALCZEWSKA-MALEC M, DREVON CA, HALL W, LOVEGROVE JA, KARLSTROM B, RISÉRUS U, ROCHE HM: Obesity and body fat classification in the metabolic syndrome: impact on cardiometabolic risk metabotype. Obesity (Silver Spring) 21: E154-E161, 2013.

SAVVA SC, LAMNISOS D, KAFATOS AG: Predicting cardiometabolic risk: waist-to-height ratio or BMI. A metaanalysis. Diabetes Metab Syndr Obes 6: 403-419, 2013. 
SETHOM MM, FARES S, FEKI M, HADJ-TAIEB S, ELASMI M, OMAR S, SANHAJI H, JEMAA R, KAABACHI $\mathrm{N}$ : Plasma fatty acids profile and estimated elongase and desaturases activities in Tunisian patients with the metabolic syndrome. Prostaglandins Leukot Essent Fatty Acids 85: 137-141, 2011.

THE R DEVELOPMENT CORE TEAM: R: A language and environment for statistical computing. R Foundation for Statistical Computing, Vienna, Austria. URL http://www.r-project.org/, 2014.

THOMPSON FE, SUBAR EF: Dietary Assessment Methodology. In: Nutrition in the Prevention and Treatment of Disease. $3^{\text {rd }}$ Edition. AM COULSTON, CJ BOUSHEY, M FERRUZZI (eds), Elsevier, Amsterdam, Boston, Heidelberg, 2013, pp 5-46.

TVRZICKÁ E, VECKA M, STAŇKOVÁ B, ŽÁK A: Analysis of fatty acids in plasma lipoproteins by gas chromatography-flame ionisation detection. Quantitative aspects. Anal Chim Acta 465: 337-350, 2002.

VANHALA M, SALTEVO J, SOININEN P, KAUTAINEN H, KANSAS AJ, ALA-KORPELA M, MÄNTYSELKÄ P: Serum omega- 6 polyunsaturated fatty acids and the metabolic syndrome: a longitudinal population-based cohort study. Am J Epidemiol 176: 253-260, 2012.

VAŘEKA T, VECKA M, JIRÁK R, TVRZICKÁ E, MACÁŠEK J, ŽÁK A, ZEMAN M: Plasma fatty acid profile in depressive disorder resembles insulin resistance state. Neuro Endocrinol Lett 33 (Suppl 2): 83-86, 2012.

VÁVROVÁ L, KODYDKOVÁ J, ZEMAN M, DUŠEJOVSKÁ M, MACÁŠEK J, STAŇKOVÁ B, TVRZICKÁ E, ŽÁK A: Altered activities of antioxidant enzymes in patients with metabolic syndrome. Obes Facts 6: 39-47, 2013.

VESSBY B: Dietary fat, fatty acid composition in plasma and the metabolic syndrome. Curr Opin Lipidol 14: 15-19, 2003.

WALSH MC, MCLOUGHLIN GA, ROCHE HM, FERGUSON JF, DREVON CA, SARIS WH, LOVEGROVE JA, RISÉRUS U, LÓPEZ-MIRANDA J, DEFOORT C, KIEĆ-WILK B, BRENNAN L, GIBNEY MJ: Impact of geographical region on urinary metabolomic and plasma fatty acid profiles in subjects with the metabolic syndrome across Europe: the LIPGENE study. Br J Nutr 111: 424-431, 2014.

WARD JH JR: Hierarchical grouping to optimize an objective function. J Amer Statist Assoc 58: 236-244, 1963.

WARENSJÖ E, RISÉRUS U, VESSBY B: Fatty acid composition of serum lipids predicts the development of the metabolic syndrome in men. Diabetologia 48: 1999-2005, 2005.

WARENSJÖ E, SUNDSRÖM J, LIND L, VESSBY B: Factor analysis of fatty acids in serum lipids as a measure of dietary fat quality in relation to the metabolic syndrome in men. Am J Clin Nutr 84: 442-448, 2006.

WU JH, LEMAITRE RN, IMAMURA F, KING IB, SONG X, SPIEGELMAN D, SISCOVICK DS, MOZAFFARIAN D: Fatty acids in the de novo lipogenesis pathway and risk of coronary heart disease: the Cardiovascular Health Study. Am J Clin Nutr 94: 431-438, 2011.

ZONG G, YE X, SUN L, LI H, YU Z, HU FB, SUN Q, LIN X: Associations of erythrocyte palmitoleic acid with adipokines, inflammatory markers, and the metabolic syndrome in middle-aged and older Chinese. Am J Clin Nutr 96: 970-976, 2012.

ŽÁK A, VECKA M, TVRZICKÁ E, HRUBÝ M, NOVÁK F, PAPEŽOVÁ H, LUBANDA H, VESELÁ L, STAŇKOVÁ B: Composition of plasma fatty acids and non-cholesterol sterols in anorexia nervosa. Physiol Res 54: 443-451, 2005.

ŽÁK A, TVRZICKÁ E, VECKA M, JÁCHYMOVÁ M, DUFFKOVÁ L, STAŇKOVÁ B, VÁVROVÁ L, KODYDKOVÁ J, ZEMAN M: Severity of metabolic syndrome unfavorably influences oxidative stress and fatty acid metabolism in men. Tohoku J Exp Med 212: 359-371, 2007. 